\title{
Pulmonary Valve Regurgitant Fraction
}

National Cancer Institute

\section{Source}

National Cancer Institute. Pulmonary Valve Regurgitant Fraction. NCI Thesaurus. Code C127588.

A quantitative measurement of the amount of retrog rade blood flow across the orifice of the pulmonic valve expressed as a percentage of the anterograde flow. 